\title{
Forensically informative nucleotide sequencing (FINS) for the authentication of Chinese medicinal materials
}

\author{
Ming Li ${ }^{1}$, Kalin Yan-Bo Zhang ${ }^{2}$, Paul Pui-Hay But ${ }^{3}$ and Pang-Chui Shaw ${ }^{1,3^{*}}$
}

\begin{abstract}
Chinese medicinal materials may be authenticated by molecular identification. As a definitive approach to molecular identification of medicinal materials, forensically informative nucleotide sequencing (FINS) comprises four steps, namely (1) DNA extraction from biological samples, (2) selection and amplification of a specific DNA fragment, (3) determination of the sequence of the amplified DNA fragment and (4) cladistic analysis of the sample DNA sequence against a DNA database. Success of the FINS identification depends on the selection of DNA region and reference species. This article describes the techniques and applications of FINS for authenticating Chinese medicinal materials.
\end{abstract}

\section{Background}

World Health Organization estimates that $70-80 \%$ of the population in the developed countries have used some forms of alternative or complementary medicine [1]. Adulteration and misuse of Chinese medicinal products may be due to (a) accidental substitution due to the similarity of organoleptic characters, (b) inconsistent naming in local areas, (c) intentional substitution of expensive materials by less expensive items and (d) different use of substitutes in local areas. Conventional authentication methods based on organoleptic features and chemical constituents are influenced by various factors such as growing stages, environmental factors and post-harvest processing.

Molecular techniques have been employed to authenticate medicinal materials since the mid 1990s [2]. Molecular techniques, such as DNA fingerprinting, DNA sequencing and DNA microarray, have been applied extensively to authenticate Chinese medicinal materials with a number of these applications having been patented and commercialized [3]. DNA sequencing can retrieve the maximum molecular information from a particular DNA region. Polymorphism of nucleotide

\footnotetext{
* Correspondence: pcshaw@cuhk.edu.hk

${ }^{1}$ State Key Laboratory of Phytochemistry and Plant Resources in West China (CUHK), Institute of Chinese Medicine, The Chinese University of Hong Kong, Shatin, New Territories, Hong Kong SAR, China

Full list of author information is available at the end of the article
}

sequences provides information to distinguish closely related species from distantly related species and between genuine medicinal materials and adulterants.

Forensically informative nucleotide sequencing (FINS), a technique that combines DNA sequencing and phylogenetic analysis, is used to identify samples based on informative nucleotide sequences. The concept of FINS was first proposed by Bartlett and Davidson in 1992 to identify the origin of animal food products and has since been extensively applied in forensic investigations $[4,5]$. In the past decade, FINS has been applied to identify and authenticate the Chinese medicinal materials with species-specific DNA regions [6-8].

This article describes the techniques and applications of FINS in authenticating Chinese medicinal materials.

\section{Performing FINS}

A defined DNA sequence from examined specimen is obtained and compared with suitable reference sequences from a reliable database using a phylogenetic analysis to identify the tested material [4]. Four basic steps are involved in FINS, namely (1) DNA extraction from biological samples, (2) selection and amplification of a specific DNA fragment, (3) determination of nucleotide sequences and (4) identification using a phylogenetic analysis against a sequence database. Materials used to construct the reference database should be properly identified fresh materials or authentic preserved 
specimens. The total DNA can be isolated by either DNA extraction or DNA release [9]. A general workflow of FINS is given in Figure 1.

\section{DNA extraction from biological samples}

DNA extraction refers to an invasive method that extracts DNA from tissues and cells via physical disruption and/or chemical fractionation. Cetyl trimethylammonium bromide (CTAB) and phenol/chloroform extraction [10] was employed by a number of commercial kits for DNA extraction. For example, DNA from

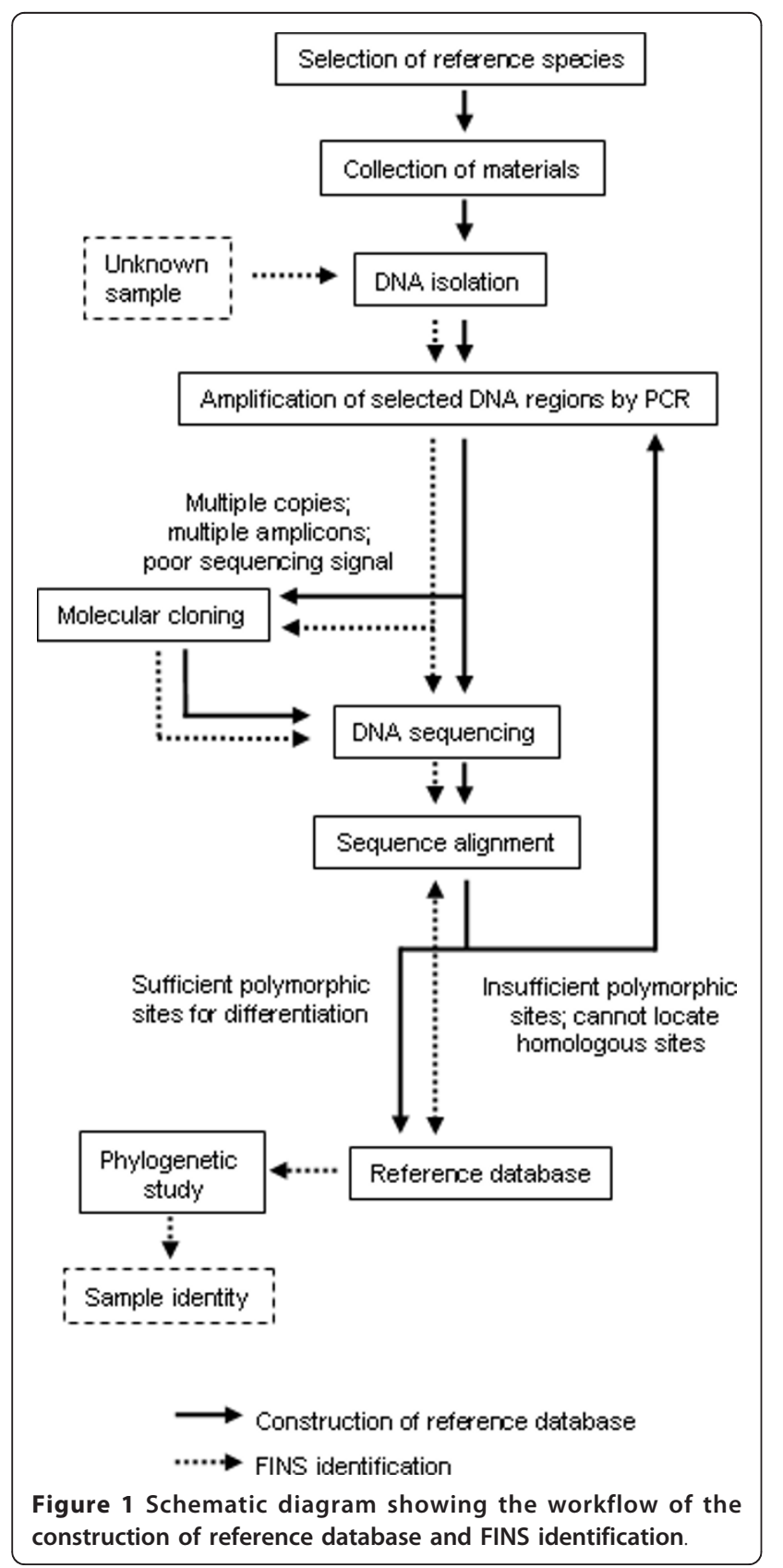

highly processed Chinese medicinal materials, such as the mule skin extract Asini Corii Colla (Ejiao) [11].

DNA release, a non-invasive method that allows DNA to release from a sample into a solution without destruction, is particularly useful for obtaining DNA from important voucher specimens. DNA release is also used to investigate samples by analyzing the environmental DNA or the preservative, as demonstrated by recent studies of DNA detection from the water in which frogs (Rana catesbeiana) live and from worms (Hypopta agavis) preserved in 95\% ethanol $[12,13]$. The quantity and quality of the obtained DNA is a major concern with this method. While purification may be achieved by commercially available kits, the yield of DNA is quite minute and should be stored in safe conditions (freezing, cyanide and ethanol), certain chemicals that can damage DNA, such as ethyl acetate or formaldehyde, should be avoided [14].

\section{Selection and amplification of a specific DNA fragment}

Usually, only a small amount of DNA can be extracted or released from highly processed or improperly stored Chinese medicinal materials. Polymerase chain reaction (PCR) can produce a sufficient amount of a specific DNA fragment obtained from a tiny amount of DNA extract. The selection of a DNA region for amplification is one of the crucial factors for FINS because the resolution of FINS depends heavily on the variability and the number of informative sites of the DNA sequences of the tested samples and reference materials. As the evolutionary rates of different DNA regions vary, DNA regions with sufficient variability are essential for providing a high resolution result. Rapidly evolving regions among taxonomic groups can be used for the identification at the genus or species level. Slowly evolving regions among groups can be used to differentiate at the section or family level. An ideal DNA region for identifying Chinese medicinal materials should have high inter-specific variation but low intra-specific variation and have sufficient informative polymorphic sites to allow differential sequence alignment among the samples and the reference species. The evolutionary rate of the same DNA region may vary among animals, plants and fungi. For example, mitochondrial cytochrome $\mathrm{c}$ oxidase subunit $1(\mathrm{COI})$ is suitable for the identification of specific animal species [15]; however, it is not suitable for most plants as few polymorphic sites are found across the $1.4 \mathrm{~kb} C O I$ sequences [16], probably due to the slow mutation rate [17]. Thus, prior knowledge of the evolutionary rates of various DNA regions facilitates the selection of an appropriate DNA region. In the past few years, short DNA sequences for global barcoding of species have been proposed [15]. For example, the DNA barcodes for animals is COI and for fungi is ITS; the 
core DNA barcodes for plants are chloroplast large subunit of ribulose-bisphosphate carboxylase gene $(r b c L)$ and chloroplast maturase $\mathrm{K}$ coding region (matK), while chloroplast trnH-psbA intergenic spacer (trnH-psbA) and nuclear internal transcribed spacer (ITS) are supplementary DNA barcodes for plants $[15,18,19]$. Recent studies suggested that ITS should be incorporated into the core DNA barcode for seed plants [20-22]. These DNA barcodes have also been commonly applied to identify medicinal materials and should be considered as the primary DNA target region for FINS [23]. Chinese medicinal materials are often dried or processed, which may affect the quality and quantity of the extractable DNA. A shorter DNA region should be considered for samples with degraded DNA. The universal primers for PCR amplification of some commonly used regions in FINS are listed in Table 1.

\section{Determination of nucleotide sequences}

DNA sequencing is the most direct approach to obtaining maximum genetic information of the amplified DNA regions. With significantly lowered costs and time, DNA sequencing is now routinely used to identify medicinal materials. The amplified and purified DNA fragments may be sequenced directly; however, molecular cloning may be applied in some cases. Cloning is required if (1) some DNA regions (e.g. ITS and 5S rRNA gene spacer) have non-homogenous multiple copies or secondary structures [24,25]; (2) non-specific PCR amplification generates multiple amplicons of similar size; (3) there is simultaneous amplification of DNA from samples and fungal contaminants (e.g. due to improper storage) and (4) there is poly-A/T structure (e.g. in $\operatorname{trn} H-p s b A$ ) interfering with the DNA sequencing [26].

\section{Phylogenetic analysis with reference to a sequence database}

A sequence database is necessary because a successful application of FINS relies on the comparison of DNA sequences among the samples and reference species. Phylogenetic analyses of many taxa using various DNA regions have been performed, providing useful reference for FINS. Our group has recently constructed an online Medicinal Materials DNA Barcoding Database http://

Table 1 Universal primers for PCR amplification of commonly used DNA regions

\begin{tabular}{|c|c|c|c|}
\hline \multirow{2}{*}{$\begin{array}{l}\text { Region } \\
5 S \text { rDNA spacer }\end{array}$} & \multicolumn{2}{|c|}{ Primer $\left(5^{\prime}>3^{\prime}\right)$} & \multirow{2}{*}{$\begin{array}{l}\text { Reference } \\
{[34]}\end{array}$} \\
\hline & $\mathrm{S}-1$ & GGATTCGTGCTTGGGCGAGAGTAGTA & \\
\hline & AS-1 & TGCGATCATACCAGCACTAAGGATCC & \\
\hline \multirow[t]{2}{*}{$12 \mathrm{~S}$ rDNA } & Fwd & CAAACTGGGATTAGATACCCCACTAT & {$[35]$} \\
\hline & Rev & GAGGGTGACGGGCGGTGTGT & \\
\hline \multirow[t]{2}{*}{$16 \mathrm{~S}$ rDNA } & Fwd & CGCCTGTITATCAAAAACAT & {$[36]$} \\
\hline & Rev & CTCCGGTTTGAACTCAGATC & \\
\hline \multirow[t]{2}{*}{$18 \mathrm{~S}$ rDNA } & $18 \mathrm{SF}$ & CAACCTGGTTGATCCTGCCAGT & {$[37]$} \\
\hline & 18SR & CTGATCCTTCTGCACCTTCACCTAC & \\
\hline \multirow[t]{2}{*}{$\mathrm{COl}$} & LCO1490 & GGTCAACAAATCATAAAGATATTGG & [15] \\
\hline & $\mathrm{HCO} 2198$ & TAAACTTCAGGGTGACCAAAAAATCA & \\
\hline \multirow[t]{2}{*}{ Cyt b } & mcb398 & TACCATGAGGACAAATATCATTCTG & {$[38]$} \\
\hline & Rev & CCTCCTAGTTTGTTAGGGATTGATCG & \\
\hline \multirow[t]{2}{*}{ ITS } & ITS4 & TCCTCCGCTTATTGATATGC & {$[18]$} \\
\hline & ITS5a & CCTTATCATTTAGAGGAAGGAG & \\
\hline \multirow[t]{2}{*}{ ITS-1 } & $18 d$ & CACACCGCCCGTCGCTCCTACCGA & {$[39]$} \\
\hline & $5.8 \mathrm{c}$ & TTGCGTTCAAAGACTCGATG & \\
\hline \multirow[t]{2}{*}{ ITS-2 } & $5.8 \mathrm{~d}$ & AACCATCGAGTCTITGAACGCA & [39] \\
\hline & $28 c c$ & ACTCGCCGTTACTAGGGGAA & \\
\hline \multirow[t]{2}{*}{ MatK } & 3F_KIM f & CGTACAGTACTITTGTGTTACGAG & [19] \\
\hline & 1R_KIM r & ACCCAGTCCATCTGGAAATCTTGGTTC & \\
\hline \multirow[t]{2}{*}{ Mitochondrial control region } & L15998 & TACCCCAAACTCCCAAAGCTA & [40] \\
\hline & $\mathrm{CSBDH}$ & TGAATTAGGAACCAGATGCCAG & \\
\hline \multirow[t]{2}{*}{ TrnH-psbA } & psbA3'f & GTTATGCATGAACGTAATGCTC & [18] \\
\hline & trnHf & CGCGCATGGTGGATTCACAATCC & \\
\hline \multirow[t]{2}{*}{ TrnL-trnF } & Tab C & CGAAATCGGTAGACGCTACG & [41] \\
\hline & Tab F & ATTTGACTGGTGACACGAG & \\
\hline \multirow[t]{2}{*}{ Rbcl } & rbcLa_F & ATGTCACCACAAACAGAGACTAAAGC & [19] \\
\hline & rbcLa_R & GTAAAATCAAGTCCACCRCG & \\
\hline
\end{tabular}


www.cuhk.edu.hk/icm/mmdbd.htm, which contains over 20,000 DNA sequences of 1,300 medicinal species found in the Pharmacopoeia of the People's Republic of China and the United States Pharmacopoeia [27]. DNA sequences can also be found in the open access NCBI GenBank http://www.ncbi.nlm.nih.gov/genbank, EMBL Nucleotide Sequence Database http://www.ebi.ac.uk/ embl as well as the Chloroplast Genome Database http://chloroplast.cbio.psu.edu. With the vast amount of sequence data, it is possible to roughly identify any unknown sample even if the sequence of its source species is not yet available. However, the quality of publicly available DNA sequences could sometimes be incorrect or derived from wrongly identified species $[6,28,29]$. Generation of tailor-made reference sequences is essential if the concerned reference sequences do not exist and high resolution identification is required.

The original idea of FINS is to perform phylogenetic analysis of unknown samples together with the reference species to trace their source origin [4], which is different from molecular identification based solely on multiple sequence alignment and comparison of polymorphic sites. FINS emphasizes the use of phylogenetic analysis to identify species via phylograms [4]. In general, phylogenetic analysis carefully selects sequence alignment to find the informative homologous sites for subsequent analysis. Phylogenetic trees are then constructed using tree construction methods, such as maximum parsimony (MP), maximum likelihood (ML) and Bayesian analysis, to reflect the evolutionary history of the concerned taxa. Available computer programs for constructing multiple sequence alignment and phylogenetic analysis are AlignM, ClustalW, BioEdit, PAUP and MEGA [30].

To identify medicinal materials, FINS users would rather identify a sample than its phylogenetic relationship with the reference species. The topology of the phylogram is the major concern and the phylogenetic relationship among the reference species is less focused in FINS identification. It was suggested that DNA distance-based methods are preferred to phylogeny-based methods in the application of FINS for identification [31]. The DNA distance-based method provides similarities between the reference and the unknown species whereas the phylogeny-based method explores the evolutionary history of the species. The major difference between these two methods lies in the way that the DNA sequences are analyzed. Phylogenetic relationship analysis, such as maximum parsimony and maximum likelihood, uses a matrix of discrete phylogenetic informative characters or statistical models to infer the optimal phylogenetic trees of selected taxa. Distance-matrix methods, such as unweighed pair-group mean analysis (UPGMA) and neighbor-joining (NJ), calculate the genetic distance from multiple sequence alignments to determine the similarities among reference sequences. A cladogram is then constructed based on the pair-wise distance values to build up the relationship of similarity. The distance-matrix methods are simple to implement and do not invoke any evolutionary indications because similar looking species may not necessarily be phylogenetically related (i.e. convergent evolution).

\section{Applications of FINS in Chinese medicinal materials}

Over 800 medicinal species are officially recorded in the Pharmacopoeia of the People's Republic of China [32]. Some of these Chinese medicinal materials are economically important and ecologically valuable, such as Dendrobii Caulis (Shihu), while some others are highly toxic, such as Aristolochiae Fructus (Madouling) and Radix Tripterygii Wilfordii (Leigongteng). FINS is one of the most definitive methods to ensure they are used safely and to protect consumers from adulteration. Over the years, FINS has been used to identify economically important materials and ecologically valuable species, as well as toxic and commonly used Chinese medicinal materials. Examples of the identification of these Chinese medicinal materials using FINS are given in Table 2.

\section{Requirements for FINS used to authenticate Chinese medicinal materials}

FINS has four major requirements on its application in identifying Chinese medicinal materials. Firstly, the success of FINS identification is highly dependent on the quality and amount of the reference sequences $[6,28,29]$. Confirmation of the authenticity of the reference sequences or generation of tailor-made sequences may be costly and time-consuming. Secondly, FINS requires a reference database to identify any single Chinese medicinal material. Therefore, it is important to select and/ or construct various databases with different reference species and different DNA regions to identify a mixture of Chinese medicinal materials. Thirdly, similar to other molecular identification techniques, FINS requires sufficient amount of good quality DNA. Some Chinese medicinal materials are derived from various plant parts with low DNA content and that were highly processed (e.g. by heat, boil or sun-dry). As a result, DNA can be damaged to the point where only very short fragments $(<200$ base pair) are left $[11,33]$. These short DNA fragments may not possess sufficient informative characters for high resolution FINS identification. ITS2 may be a good region for FINS because of its small size (200-300 base pair) and its high variability in plants and animals [20], although molecular cloning is needed to overcome the problem of multiple copies and secondary structure $[24,25]$. Fourthly, contamination of fungal species is common in Chinese medicinal materials. Specific primers are required for the materials without the 
Table 2 Representative examples of FINS identification of Chinese medicinal materials

\begin{tabular}{|c|c|c|c|c|}
\hline Year & Test material & DNA locus & Major finding & Reference \\
\hline 2002 & $\begin{array}{l}\text { Shihu samples and Dendrobium } \\
\text { species }\end{array}$ & ITS & 4 inspected samples of 'Fengdou' were identified & [7] \\
\hline 2003 & $\begin{array}{l}\text { Rhinoceros horns, Rhinoceros } \\
\text { species and other mammals }\end{array}$ & Cyt b & 2 samples were white rhinoceros and 4 samples were dark rhinoceros & [8] \\
\hline 2004 & $\begin{array}{l}\text { Snake blood and meat, and } 90 \\
\text { snake species }\end{array}$ & Cyt b & 6 unknown samples were identified as Python molurus and P. reticulates & {$[42]$} \\
\hline 2005 & $\begin{array}{l}\text { Chinese sika deer and Cervus } \\
\text { Nippon subspecies }\end{array}$ & $\begin{array}{l}\text { Mitochondrial } \\
\text { control region }\end{array}$ & $\begin{array}{l}2 \text { suspected samples were derived from wild population of C. Nippon } \\
\text { kopschi }\end{array}$ & [43] \\
\hline 2007 & $\begin{array}{l}\text { Fresh and herbal samples of } \\
\text { Dangshen }\end{array}$ & $5 \mathrm{~S}$ rDNA spacer & $\begin{array}{l}2 \text { samples of Hong Dangshen were identified as Codonopsis pilosula var. } \\
\text { modesta }\end{array}$ & [44] \\
\hline 2008 & Snake venom & $165 \mathrm{rDNA}$ & 1 snake venom was identified as derived from Naja atra & [45] \\
\hline \multirow[t]{4}{*}{2009} & $\begin{array}{l}\text { Shihu samples and Dendrobium } \\
\text { species }\end{array}$ & ITS & $\begin{array}{l}\text { Identification of } 10 \text { Shihu samples: } 6 \text { were D. officinale, } 1 \text { was D. nobile } \\
\text { and } 3 \text { were D. denneanum }\end{array}$ & [46] \\
\hline & $\begin{array}{l}\text { Shihu samples and Dendrobium } \\
\text { species }\end{array}$ & MatK & Identification of 4 Shihu samples: 3 were D. officinale and 1 were D. nobile & [47] \\
\hline & $\begin{array}{l}\text { Shihu samples and Dendrobium } \\
\text { species }\end{array}$ & $\operatorname{TrnH}-p s b A$ & Identification of various 'Fengdou' Dendrobium species 20 shihu samples & [48] \\
\hline & Snake venom & $165 \mathrm{rDNA}$ & 4 snake venom samples were all genuine & [49] \\
\hline \multirow[t]{2}{*}{2010} & $\begin{array}{l}\text { Baihuasheshecao samples and } \\
\text { Hedyotis species }\end{array}$ & ITS & 4 out of 7 samples were adulterated by $\mathrm{H}$. corymbosa & [50] \\
\hline & $\begin{array}{l}\text { Madouling samples, Aristolochia, } \\
\text { Cardiocrinum and Lilium species }\end{array}$ & $\begin{array}{l}\text { TrnH-psbA, trnL- } \\
\operatorname{trnF}\end{array}$ & $\begin{array}{l}2 \text { out of } 4 \text { Madouling samples from Taiwan and Yunnan were substituted } \\
\text { by C. giganteum var. yunnanense }\end{array}$ & [51] \\
\hline \multirow[t]{2}{*}{2011} & $\begin{array}{l}\text { Cordyceps samples and related } \\
\text { Cordyceps species }\end{array}$ & $\begin{array}{l}\text { EF-1 } \alpha, \text { ITS, } \\
\operatorname{nrLSU}, \text { rpb } 1\end{array}$ & $\begin{array}{l}3 \text { Cordyceps samples were genuine derived from C. sinensis, } 5 \text { samples } \\
\text { were C. gunni from China and } 1 \text { sample was C. gunni from Tasmania }\end{array}$ & [6] \\
\hline & $\begin{array}{l}\text { Leigongteng samples, Tripterygium } \\
\text { and Celastrus species }\end{array}$ & $\begin{array}{l}5 S \text { rDNA spacer, } \\
\text { ITS }\end{array}$ & $\begin{array}{l}3 \text { samples of Leigongteng were genuine herb derived from T. wilfordii, } 2 \\
\text { samples were adulterants derived from Celastrus species }\end{array}$ & [52] \\
\hline
\end{tabular}

amplification of the contaminants when nuclear DNA regions, such as ITS and 5S rRNA gene spacer, are used.

\section{Conclusion}

Using to authenticate genuine medicinal materials, FINS actually traces the identifies of DNA samples at different taxonomic levels. High resolution FINS is expected to be useful in the authentication and quality control of Chinese medicinal materials.

\begin{abstract}
Abbreviations
COl: cytochrome c oxidase subunit 1; CTAB: cetyl trimethylammonium bromide; cyt b: cytochrome b gene; EF-1a: elongation factor 1a: FINS: forensically informative nucleotide sequencing; ITS: internal transcribed spacer; matK: maturase K; ML: maximum likelihood; MP: maximum parsimony; NJ: neighbor-joining; nrLSU: nuclear ribosomal large subunit; PCR: polymerase chain reaction; $r b c L$ : large subunit of ribulose-bisphosphate carboxylase; rpb1: largest subunit of RNA polymerase II; $\operatorname{trnH}-p s b A$ : $\operatorname{trnH}-p s b A$ intergenic spacer; trnL-trnF: trnL-trnF intergenic spacer; UPGMA: unweighed pair-group mean analysis.
\end{abstract}

\section{Acknowledgements}

We are indebted to Dr. David Wilmshurst of the Research Administration Office of The Chinese University of Hong Kong for his editing of the manuscript. Our research projects in FINS were partially supported by a subgrant for the Large-scale Scientific Facilities of the Chinese Academy of Sciences (2009-LSF-GBOWS-01)

\section{Author details}

'State Key Laboratory of Phytochemistry and Plant Resources in West China (CUHK), Institute of Chinese Medicine, The Chinese University of Hong Kong, Shatin, New Territories, Hong Kong SAR, China. ${ }^{2}$ School of Chinese Medicine,
The University of Hong Kong, Pokfulam, Hong Kong SAR, China. ${ }^{3}$ School of Life Sciences, The Chinese University of Hong Kong, Shatin, New Territories, Hong Kong SAR, China.

\section{Authors' contributions}

ML drafted the manuscript. PCS, KYPZ and PPHB critically revised the manuscript. All authors read and approved the final version of the manuscript.

\section{Competing interests}

The authors declare that they have no competing interests.

Received: 4 August 2011 Accepted: 9 December 2011

Published: 9 December 2011

\section{References}

1. World Health Organization: Traditional Medicine. Fact Sheet 2008, N134.

2. Shaw PC, But PPH: Authentication of Panax species and their adulterants by random-primed polymerase chain reaction. Planta Med 1995, 61:466-469.

3. Shaw PC, Wong KL, Chan AW, Wong WC, But PPH: Patent applications for using DNA technologies to authenticate medicinal herbal material. Chin Med 2009, 4:21.

4. Bartlett SE, Davidson WS: FINS (forensically informative nucleotide sequencing): a procedure for identifying the animal origin of biological specimens. Biotechniques 1992, 12:408-411.

5. Sahajpal V, Goyal SP: Identification of a forensic case using microscopy and forensically informative nucleotide sequencing (FINS): A case study of small Indian civet (Viverricula indica). Sci Justice 2009, 50:94-97.

6. Chan WH, Ling KH, Chiu SW, Shaw PC, But PPH: Molecular Analyses of Cordyceps gunnii in China. J Food Drug Anal 2011, 19:18-25.

7. Ding XY, Wang ZT, Xu H, Xu LS, Zhou KY: Database establishment of the whole rDNA ITS region of Dendrobium species of "fengdou" and authentication by analysis of their sequences. YaoXueXueBao 2002, 37:567-573. 
8. Hsieh HM, Huang LH, Tsai LC, Kuo YC, Meng HH, Linacre A, Lee JC: Species identification of rhinoceros horns using the cytochrome $b$ gene. Forensic Sci Int 2003, 136:1-11.

9. Hajibabaei M, deWaard JR, Ivanova NV, Ratnasingham S, Dooh RT, Kirk SL, Mackie PM, Hebert PD: Critical factors for assembling a high volume of DNA barcodes. Phil Trans R Soc B 2005, 360:1959-1967.

10. Kang HW, Cho YG, Yoon UH, Eun MY: A rapid DNA extraction method for RFLP and PCR analysis from a single dry seed. Plant Mol Bio Rep 1998, 16:1-9.

11. LV P, Zhou X, You J, Ye BC, Zhang Y: Extraction of trace amount of severely degraded DNA. Z Naturforsch C 2009, 64:581-589.

12. Ficetola GF, Miaud C, Pompanon F, Taberlet P: Species detection using environmental DNA from water samples. Bio Letters 2008, 4:423-425.

13. Shokralla S, Singer GAC, Hajibabaei M: Direct PCR amplification and sequencing of specimen's DNA from preservative ethanol. Biotechniques 2010, 44:305-306.

14. Prendini L, Hanner R, DeSalle R: Obtaining, storing and archiving specimens and tissue samples for use in molecular studies. In Techniques in Molecular Evolution and Systematics. Edited by: DeSalle R, Giribet G, Wheeler WC. Basel: Birkhaeuser Verlag AG; 2002:176-248.

15. Hebert PD, Cywinska A, Ball SL, deWaard JR: Biological identifications through DNA barcodes. Proc Biol Sci 2003, 270:313-321.

16. Cho Y, Mower JP, Qiu YL, Palmer JD: Mitochondrial substitution rates are extraordinarily elevated and variable in a genus of flowering plants. $P$ Natl Acad Sci USA 2004, 101:17741-17746.

17. Wolfe KH, Li WH, Sharp PM: Rates of nucleotide substitution vary greatly among plant mitochondrial, chloroplast, and nuclear DNAs. P Natl Acad Sci USA 1987, 84:9054-9058

18. Kress WJ, Wurdack KJ, Zimmer EA, Weigt LA, Janzen DH: Use of DNA barcodes to identify flowering plants. P Natl Acad Sci USA 2005, 102:8369-8374

19. CBOL Plant Working Group: A DNA barcode for land plants. P Natl Acad Sci USA 2009, 106:12794-12797.

20. Chen S, Yao H, Han J, Liu C, Song J, Shi L, Zhu Y, Ma X, Gao T, Pang X, Luo K, Li Y, Li X, Jia X, Lin Y, Leon C: Validation of the ITS2 region as a novel DNA barcode for identifying medicinal plant species. PloS One 2010, 5:e8613.

21. China Plant BOL Group, Li DZ, Gao LM, Li HT, Wang H, Ge XJ, Liu JQ, Chen ZD, Zhou SL, Chen SL, Yang JB, Fu CX, Zeng CX, Yan HF, Zhu YJ, Sun YS, Chen SY, Zhao L, Wang K, Yang T, Duan GW: Comparative analysis of a large dataset indicates that internal transcribed spacer (ITS) should be incorporated into the core barcode for seed plants. P Natl Acad SC USA .

22. Hollingsworth PM: Refining the DNA barcode for land plants. P Natl Acad Sci USA

23. Li M, Cao H, But PPH, Shaw PC: Identification of herbal medicinal materials using DNA barcodes. J Syst Evol 2011, 49:271-283.

24. Alvarez I, Wendel JF: Ribosomal ITS sequences and plant phylogenetic inference. Mol Phylogenet Evol 2003, 29:417-434.

25. Baldwin BG, Sanderson MJ, Porter JM, Wojciechowski MF, Campbell CS, Donoghue MJ: The ITS region of nuclear ribosomal DNA: a valuable source of evidence on angiosperm phylogeny. Ann Mo Bot Gard 1995, 82:247-277.

26. Zhu YJ, Chen SL, Yao H, Tan R, Song JY, Luo K, Lu J: DNA barcoding the medicinal plants of the genus Paris. YaoXueXueBao 2010, 45:376-382.

27. Lou SK, Wong KL, Li M, But PPH, Tsui KW, Shaw PC: Construction of an integrated web medicinal herbal material DNA database. BMC Genomics 2010, 11:402

28. Vilgalys $\mathrm{R}$ : Taxonomic misidentification in public DNA databases. NeW Phytol 2003, 160:4-5

29. Nilsson RH, Ryberg $M$, Kristiansson $E$, Abarenkov $K$, Larsson $\mathrm{KH}$, Koljalg U: Taxonomic reliability of DNA sequences in public sequence databases: a fungal perspective. PloS One 2006, 1:e59.

30. Schmitt I, Barker FK: Phylogenetic methods in natural product research. Nat Prod Rep 2009, 26:1585-1602

31. Forrest AR, Carnegie PR: Identification of gourmet meat using FINS (forensically informative nucleotide sequencing). Biotechniques 1994 $17: 24,26$.

32. State Pharmacopoeia Commission of People's Republic of China: Pharmacopoeia of the People's Republic of China Beijing: Chemical Industry Press; 2010.
33. Teletchea F, Maudet C, Hanni C: Food and forensic molecular identification: update and challenges. Trends Biotechnol 2005, 23:359-366.

34. Chen F, Chan HY, Wong KL, Wang J, Yu MT, But PPH, Shaw PC: Authentication of Saussurea lappa, an endangered medicinal material, by ITS DNA and 5S rRNA sequencing. Planta Med 2008, 74:889-892.

35. Girish PS, Anjaneyulu ASR, Viswas KN, Anand M, Rajkumar Nb, Shivakumar BM, Bhaskar S: Sequence analysis of mitochondrial 12S rRNA gene can identify meat species. Meat Sci 2004, 66:551-556.

36. Mitchell SE, Cockburn AF, Seawright JA: The mitochondrial genome of Anopheles quadrimaculatus species A: complete nucleotide sequence and gene organization. Genome 1993, 36:1058-1073.

37. Sogin ML: Amplification of ribosomal RNA genes for molecular evolution studies. In PCR Protocols: a Guide to Methods and Application. Edited by: Innis M, Gelfand DH, Sninksky J. San Diego: Academic Press; 1990:307.

38. Verma SK, Singh L: Novel universal primers establish identity of an enormous number of animal species for forensic application. Molecular Ecology Notes 2003, 3:28-31.

39. White TJ, Burns T, Lee S, Taylor JW: Amplification and direct sequencing of fungal ribosomal RNA genes for phylogenetics. In PCR protocols: A guide to methods and applications. Edited by: Innis MA, Gelfand DH, Sninsky JJ, White TJ. New York: Academic Press; 1990:315-322.

40. Vinas J, Tudela S: A validated methodology for genetic identification of tuna species (genus Thunnus). PloS One 2009, 4:e7606.

41. Taberlet P, Gielly L, Pautou G, Bouvet J: Universal primers for amplification of three non-coding regions of chloroplast DNA. Plant Mol Biol 1991, 17:1105-1109.

42. Wong KL, Wang J, But PPH, Shaw PC: Application of cytochrome b DNA sequences for the authentication of endangered snake species. Forensic Sci Int 2004, 139:49-55.

43. Wu H, Wan QH, Fang SG, Zhang SY: Application of mitochondrial DNA sequence analysis in the forensic identification of Chinese sika deer subspecies. Forensic Sci Int 2005, 148:101-105.

44. Zhang YB, Jiang RW, Li SL, Qiao CF, Han QB, Xu HX, Wong KL, But PPH, Shaw PC: Chemical and molecular characterization of Hong Dangshen, a unique medicinal material for diarrhea in Hong Kong. J Chin Pharmaceut Sci 2007, 16:202-207.

45. Chen N, Zhao SJ, Han LP: DNA molecular identification of one snake crude venom used for production. ShiZhenGuoYiGuoYao 2008, 19:1578-1580

46. Liu J, He T, Chun Z: DNA molecular identification of Herba Dendrobii and its adulterant species based on ITS sequence analysis. ZhongGuoZhongYaoZaZhi 2009, 34:2853-2856.

47. Liu J, He T, Chun Z: Analysis and authentication of chloroplast matK gene sequences of Herba Dendrobii. YaoXueXueBao 2009, 44:1051-1055.

48. Shao SG, Han L, Ma YH, Shen J, Zhang WC, Ding XY: Analysis and authentication of cpDNA psbA-trnH regions of Dendrobium species of fengdous. YaoXueXueBao 2009, 44:1173-1178.

49. Chen N, Zhao SJ: Forensic identification of snake crude venom by mtDNA analysis. ShizhenGuoYiGuoYao 2009, 20:2001-2003.

50. Li M, Jiang RW, Hon PM, Cheng L, Li LL, Zhou JR, Shaw PC, But PPH: Authentication of the anti-tumor herb Baihuasheshecao with bioactive marker compounds and molecular sequences. Food Chem 2010, 119:1239-1245

51. Li M, Ling KH, Lam H, Shaw PC, Cheng L, Techen N, Khan IA, Chang YS, But PPH: Cardiocrinum seeds as a replacement for Aristolochia fruits in treating cough. J Ethnopharmacol 2010, 130:429-432.

52. Law SK, Simmons MP, Techen N, Khan IA, He MF, Shaw PC, But PPH: Molecular analyses of the Chinese herb Leigongteng (Tripterygium wilfordii Hook. f.). Phytochemistry 2011, 72:21-26.

doi:10.1186/1749-8546-6-42

Cite this article as: Li et al:: Forensically informative nucleotide sequencing (FINS) for the authentication of Chinese medicinal materials. Chinese Medicine 2011 6:42. 